\title{
DLC-Si Protective Coatings for Polycarbonates
}

\author{
J.C. Damasceno ${ }^{\mathrm{a}}$, S.S. Camargo Jr. ${ }^{\mathrm{a} *}$, M. Cremona ${ }^{\mathrm{b}}$ \\ ${ }^{a}$ Engenharia Metalúrgica e de Materiais, Universidade Federal do Rio de Janeiro \\ C.P. 68505, 21945-970 Rio de Janeiro - RJ, Brazil \\ ${ }^{\mathrm{b}}$ Departamento de Física, Pontifícia Universidade Católica do Rio de Janeiro \\ C.P. 38071, 22454-970 Rio de Janeiro - RJ, Brazil
}

Received: January 02, 2002; Revised: September 30, 2002

\begin{abstract}
In this work, a-C:H:Si (DLC-Si) films were produced onto crystalline silicon and polycarbonate substrates by the rf-PACVD technique from gaseous mixtures of $\mathrm{CH}_{4}+\mathrm{SiH}_{4}$ and $\mathrm{C}_{2} \mathrm{H}_{2}+\mathrm{SiH}_{4}$. The effects of self-bias and gas composition upon mechanical and optical properties of the films were investigated. Micro-hardness, residual stress, surface roughness and refractive index measurements were employed for characterization. By incorporating low concentrations of silicon and by exploring the more favorable conditions for the rf-PACVD deposition technique, highly adherent DLC-Si thin films were produced with reduced internal stresses (lower than $1 \mathrm{GPa}$ ), high hardness (around $20 \mathrm{GPa}$ ) and high deposition rates (up to $10 \mu \mathrm{m} / \mathrm{h}$ ). Results that show the technological viability of this material for application as protective coatings for polycarbonates are also discussed.
\end{abstract}

Keywords: thin films, DLC, chemical vapor deposition, silicon carbide, polycarbonate

\section{Introduction}

Plastics have become important materials because they can be produced in large scale and are cheaper and lighter than many other materials. Amongst those, polycarbonates are well-known, commercially available materials. Because of their excellent breakage resistance, polycarbonates have replaced glasses in many applications, such as automobile headlamps, safety shields of windows, ophthalmic lenses and sunglasses, and the like. However, their use is still limited to non-abrasive and chemical-free environments, because of their low hardness, low scratch resistance and their high susceptibility to harsh chemical conditions. To overcome this limitation, methods for producing a hard transparent protective coating on polycarbonate materials have been studied ${ }^{1-5}$, including the deposition of diamond-like amorphous carbon (DLC) films ${ }^{6-9}$.

DLC films have been successfully deposited on different kinds of substrates by several different techniques ${ }^{10,11}$. Their high hardness, low friction coefficient and high chemical inertness have made of them great candidates for wearresistant, hard coatings for many applications. Unfortunately, the high intrinsic stress of these films limits their adhesion and thickness. Silicon-incorporated diamond-like carbon films (DLC-Si) have a great potential for solving some of the major drawbacks of pure DLC films. Indeed, DLC-Si films present reduced residual internal stress ${ }^{12,13}$, high deposition rates ${ }^{14}$, good adhesion to most substrates, including various metal alloys, steels and glasses ${ }^{15-17}$ and very high hardness ${ }^{16,18,19}$.

In this work, DLC-Si films were produced onto crystalline silicon and polycarbonate substrates by the rf-PACVD technique from gaseous mixtures of $\mathrm{CH}_{4}+\mathrm{SiH}_{4}$ and $\mathrm{C}_{2} \mathrm{H}_{2}+\mathrm{SiH}_{4}$. The effects of self-bias and gas composition upon mechanical and optical properties of the films were investigated.

\section{Experimental}

Silicon-incorporated hydrogenated amorphous carbon films (DLC-Si) were deposited from gaseous mixtures of $\mathrm{CH}_{4}+\mathrm{SiH}_{4}$ and $\mathrm{C}_{2} \mathrm{H}_{2}+\mathrm{SiH}_{4}$ onto crystalline silicon and polycarbonate substrates placed on the cathode of a conventional radio frequency $(13.56 \mathrm{MHz})$ parallel plate glow discharge reactor. A gas flow of about $10 \mathrm{sccm}$ from premade mixtures with 5 vol. $\%$ of silane was fed into the reactor through mass flow controllers. During all deposition runs the electrode distance and the chamber pressure monitored by a capacitance manometer were kept fixed at $3 \mathrm{~cm}$ and 2.0 $\mathrm{Pa}$, respectively. Films with thickness between 1.5 and

*e-mail: camargo@metalmat.ufrj.br 
$3 \mu \mathrm{m}$ were produced at different self-bias voltages $\left(\mathrm{V}_{\mathrm{B}}\right)$ from $-100 \mathrm{~V}$ up to $-1000 \mathrm{~V}$. It must be noted that no temperature control of the substrate was done during deposition. Therefore, substantial heating of the substrate surface may occur as a result of its interaction with the plasma, mainly in case of depositions with high power densities.

Residual internal stress was obtained by the substrate bending method using a Dektak IIA stylus profilometer, which was also used for the thickness and surface roughness measurements. All films presented compressive stresses. Indentation of the samples was done with a Vickers diamond micro-indenter with a $0.25 \mathrm{~N}$ load during approximately 20 s keeping the indentation depth smaller than $20 \%$ of the sample thickness. Hardness was obtained from the measurement of the indentation diagonals on an optical microscope using the DIC (differential interference contrast) technique. In all cases hardness was calculated from the average of a series of 20 different indentations. All stress and hardness measurements were taken from samples deposited on silicon substrates, while roughness was determined for the films deposited on polycarbonate.

Refractive index was measured by the AbelésHacskaylo ${ }^{20}$ method using a $633 \mathrm{~nm} \mathrm{He}-\mathrm{Ne}$ laser beam. All optical measurements were made using the samples deposited on polycarbonate substrates.

\section{Results and Discussion}

Deposition rate of DLC-Si films is strongly increased when one increases the rf power density dissipated in the plasma in a similar manner to what is observed for pure a$\mathrm{C}: \mathrm{H}$ films. As can be seen in Fig. 1, the deposition rate as a function of the resulting cathode self-bias potential presents an increase of almost one order of magnitude when the selfbias voltage is varied from $-100 \mathrm{~V}$ to $-1000 \mathrm{~V}$. In addition, the deposition rate obtained when using $\mathrm{C}_{2} \mathrm{H}_{2}$ as carbonsource gas is much higher than in case of $\mathrm{CH}_{4}$. For instance, films deposited with $\mathrm{CH}_{4}$ present a maximum deposition rate of about $2.7 \mu \mathrm{m} / \mathrm{h}$ whereas with $\mathrm{C}_{2} \mathrm{H}_{2}$ a deposition rate of $10 \mu \mathrm{m} / \mathrm{h}$ was achieved keeping the other deposition conditions unchanged. Similar behavior was also observed for pure a-C:H films ${ }^{21}$ and can be explained considering the following: (a) the low ionization energies of $\mathrm{C}_{2} \mathrm{H}_{2}$ in comparison to $\mathrm{CH}_{4}$ which allows the first to react in higher quantities with the growing film surface; and (b) the increased $\mathrm{C} / \mathrm{H}$-ratio for $\mathrm{C}_{2} \mathrm{H}_{2}$ (1:1) compared with $\mathrm{CH}_{4}$ (1:4).

Figures $2 \mathrm{a}$ and $2 \mathrm{~b}$ show the behavior of surface roughness of polycarbonate samples, before and after deposition of the films, as a function of cathode self-bias and gas precursor. As one can see in these figures, the surface roughness of the polycarbonate samples is slightly raised by the plasma deposition process for $\left|\mathrm{V}_{\mathrm{B}}\right|$ up to $600 \mathrm{~V}$, maintaining acceptable low surface roughness regardless of the source

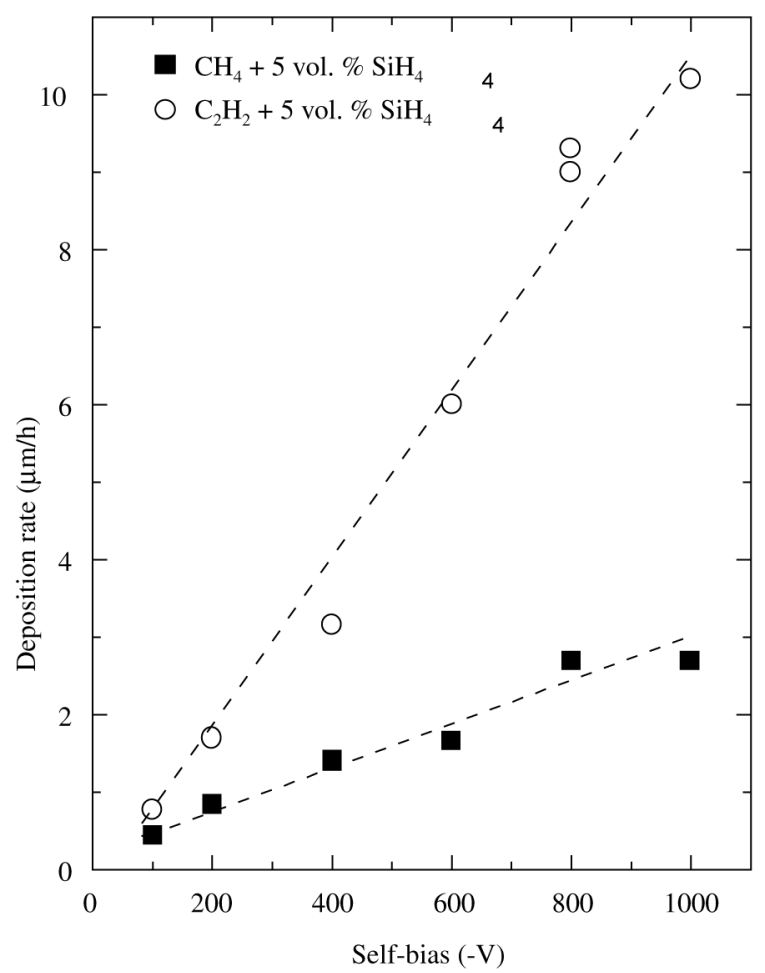

Figure 1. Deposition rate of Si-DLC films prepared from mixtures of $\mathrm{CH}_{4}+5 \mathrm{vol} \% \mathrm{SiH}_{4}$ (squares) and $\mathrm{C}_{2} \mathrm{H}_{2}+5$ vol. $\% \mathrm{SiH}_{4}$ (circles) as a function of negative self-bias voltage.

gases used. On the other hand, samples deposited with values of $\left|\mathrm{V}_{\mathrm{B}}\right|$ of $800 \mathrm{~V}$ are greatly damaged by the plasma having their surface roughness raised by almost two orders of magnitude for both gas mixtures. The surface damage of the samples can be attributed to high-energy particle bombardment when using high power densities, which can lead to substantial surface heating and fusion. For this reason, polycarbonate substrates were not used for deposition at $\mathrm{V}_{\mathrm{B}}=-1000 \mathrm{~V}$.

Residual internal stress of DLC-Si films strongly depends on the employed cathode self-bias potential, as already reported elsewhere ${ }^{22}$. In the low self-bias range the internal stress is increased when one increases the self-bias voltage, attains a maximum and then decreases monotonically for high values of self-bias, as shown in Fig. 3a. It is interesting to observe that this maximum value occurs around $\mathrm{V}_{\mathrm{B}}=-200 \mathrm{~V}$ for $\mathrm{CH}_{4}$-based films and around $\mathrm{V}_{\mathrm{B}}=-400 \mathrm{~V}$ for $\mathrm{C}_{2} \mathrm{H}_{2}$-based films. Similar behavior was also observed for pure a-C:H films ${ }^{21}$. This can be explained by considering that on impact at the surface, ions from a $\mathrm{C}_{\mathrm{n}} \mathrm{H}_{\mathrm{m}}$ gas plasma fragment into $n$ separate $\mathrm{C}^{+}$ions, evenly distributing among then the incident energy. Since the material 


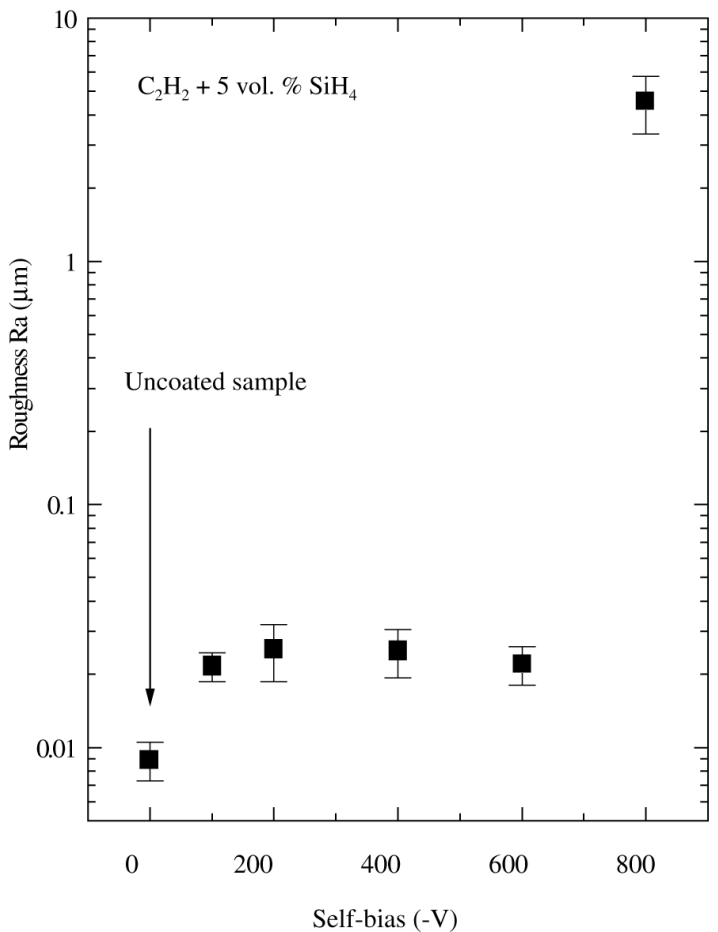

(a)

Figure 2. Surface roughness of polycarbonate samples before and after the deposition of Si-DLC films prepared from mixtures of $\mathrm{C}_{2} \mathrm{H}_{2}+5$ vol. $\% \mathrm{SiH}_{4}$ (a) and $\mathrm{CH}_{4}+5$ vol. $\% \mathrm{SiH}_{4}$; (b) as a function of negative self-bias voltage.
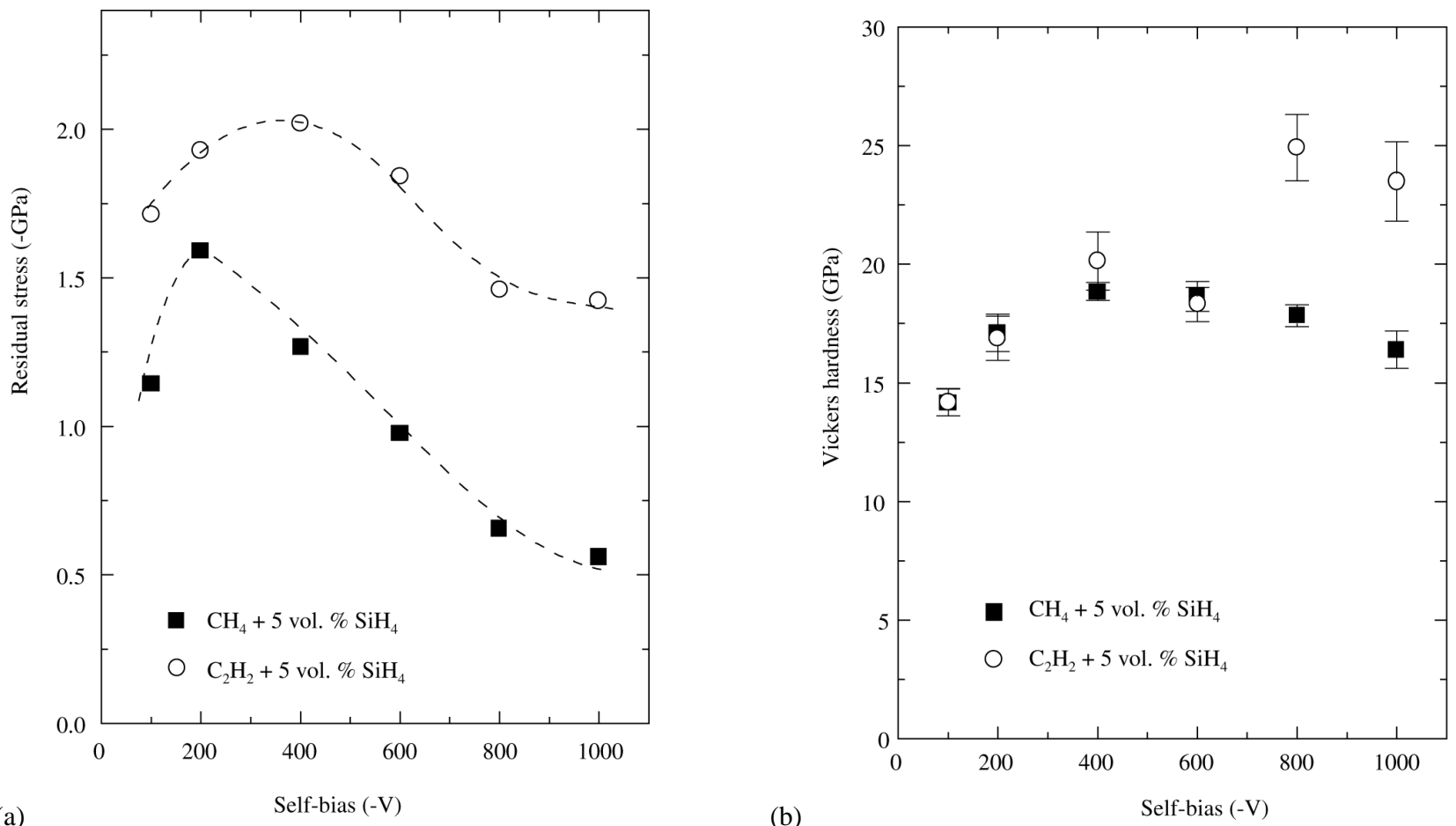

Figure 3. Residual internal stress (a) and Vickers micro hardness; (b) as a function of negative self-bias voltage of Si-DLC films prepared from mixtures of $\mathrm{CH}_{4}+5 \mathrm{vol} . \% \mathrm{SiH}_{4}$ (squares) and $\mathrm{C}_{2} \mathrm{H}_{2}+5$ vol. $\% \mathrm{SiH}_{4}$ (circles) as a function of negative self-bias voltage. 


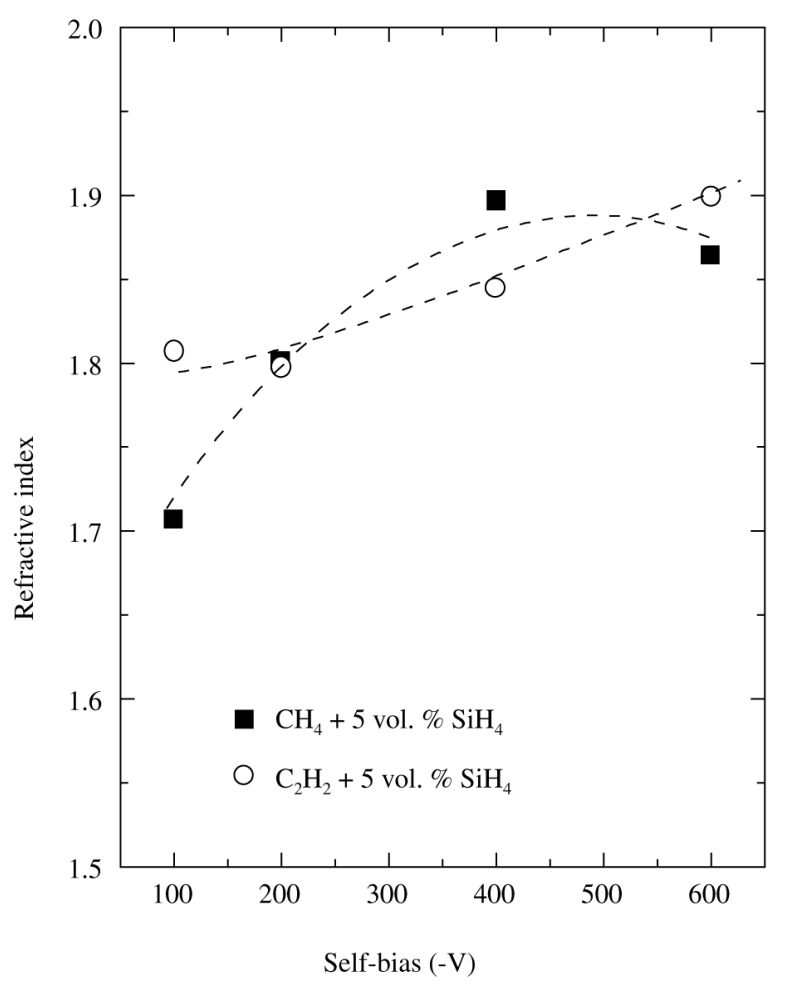

Figure 4. Refractive index of Si-DLC films prepared from mixtures of $\mathrm{CH}_{4}+5$ vol. $\% \mathrm{SiH}_{4}$ (squares) and $\mathrm{C}_{2} \mathrm{H}_{2}+5$ vol. $\% \mathrm{SiH}_{4}$ (circles) as a function of negative self-bias voltage.

densification and, consequently, the residual stress generated in the films depends directly on this energy, the point of maximum stress is shifted to higher negative self-bias values when the gas precursor is changed from $\mathrm{CH}_{4}$ to $\mathrm{C}_{2} \mathrm{H}_{2}$ because the number of carbon atoms per molecule is also increased ${ }^{23}$. In addition, residual stress values for $\mathrm{C}_{2} \mathrm{H}_{2}$-based films were found to be higher than $\mathrm{CH}_{4}$-based ones.

Figure $3 \mathrm{~b}$ shows the obtained behavior of hardness for the two series of films as a function of the cathode self-bias. As one can notice in both cases a monotonic increase of hardness is observed when the self-bias is varied from $-100 \mathrm{~V}$ up to $-400 \mathrm{~V}$. For $\left|\mathrm{V}_{\mathrm{B}}\right|>400 \mathrm{~V}$, the hardness of $\mathrm{CH}_{4}$-based films is decresead very slightly, while in case of $\mathrm{C}_{2} \mathrm{H}_{2}$-based films, higher values of hardness were obtained. Indeed, in contrast to what is generally observed for DLC films ${ }^{21,24}$ a significant reduction of hardness for high values of negative self-bias was not observed in agreement with our previous results ${ }^{22}$.

Measurements of refractive index of the films were carried out as a function of cathode self-bias and gas precursor. As can be observed in fig. 4, in case of $\mathrm{CH}_{4}$-based films there is an increase of the refractive index from 1.71 to 1.90 when the self-bias is varied from $-100 \mathrm{~V}$ to $-400 \mathrm{~V}$, and a slightly reduction to 1.86 for $\mathrm{V}_{\mathrm{B}}=-600 \mathrm{~V}$. The refractive index of $\mathrm{C}_{2} \mathrm{H}_{2}$-based films is increased monotonically from 1.81 to 1.90 when one varies the self-bias from $-100 \mathrm{~V}$ to $-600 \mathrm{~V}$. Optical measurements for $\mathrm{V}_{\mathrm{B}}=-800 \mathrm{~V}$ and $-1000 \mathrm{~V}$ could not be obtained due to the surface damage of the samples as discussed before. Obtained values of refractive index of all films are higher than the refractive index of the polycarbonate substrate $(n=1.586)$. Therefore, although these films can be good candidates for the use as protective coatings for polycarbonate, they cannot be used as anti-reflective coatings. This issue will be further investigated by varying the source gas mixture composition.

\section{Conclusions}

The viability of producing DLC-Si films deposited by PECVD as protective coatings for polycarbonate substrates has been demonstrated. A study of the influence of deposition parameters, namely self-bias and gas composition, on the properties of the films was carried out. Films deposited at high self-bias showed very high deposition rates, low stress and high hardness. However, high self-bias values leaded to surface damage of the samples. Smooth films could be obtained keeping self-bias voltages below $\left|\mathrm{V}_{\mathrm{B}}\right|=600 \mathrm{~V}$ so that to avoid surface heating and damage. Acetylene seems to be more attractive as carbon source gas since much higher deposition rates can be obtained while other properties like surface roughness, refractive index and hardness are equivalent to films deposited from methane mixtures.

\section{Acknowledgements}

This work was supported by Finep and CNPq Brazilian agencies, CNPq/DLR International Cooperation Program and DLR/BMBF (Germany).

\section{References}

1. Suchentrunk, R.; Fuesser, H.J.; Staudigl, G.; Jonke, D.; Meyer, M. Surface and Coatings Technology, v. 112, p. 351-357, 1999.

2. Lee, C.-C.; Hsu, J.-C.; Jaing, C.-C. Thin Solid Films, v. 295, p. 122-124, 1997.

3. Zajîèková, L., Buršíková, V., Janèa, J., Vacuum, v. 50, n. 1-2, p. 19-21, 1998.

4. Katsamberis, D.; Browall, K.; Iacovangelo, C.; Neumann, M.; Morgner, H. Progress in Organic Coatings, v. 34, p. 130-134, 1998.

5. Rats, D.; Hajek, V.; Martinu, L. Thin solid Films, v. 340, p. 33-39, 1999.

6. Laidani, N.; Speranza, G.; Nefedov, A.; Calliari, L.; Anderle, M. Diamond and Related Materials, v. 7, p. 1394-1402, 1998. 
7. Kimock, F.M.; Knapp, B.J. Surface and Coatings Technology, v. 56, p. 273-279, 1993.

8. Ong, H.C.; Chang, R.P.H.; Baker, N.; Oliver, W.C. Surface and Coatings Technology, v. 89, p. 38-46, 1997.

9. Park, K.J.; Chin, E.Y. Polymer Degradation and Stability, v. 68, p. 93-96, 2000.

10. Lifshitz, Y. Diamond and Related Materials, v. 8, p. 1659-1676, 1999.

11. Grill, A. Diamond and Related Materials, v. 8, p. 428-434, 1999.

12. Baia Neto, A.L.; Santos, R.A; Freire Jr., F.L.; Camargo Jr., S.S.; Carius, R.; Finger, F.; Beyer, W. Thin Solid Films, v. 293, p. 206, 1997.

13. Gangopadhyay, A.K.; Willermet, P.A.; Tamor, M.A.; Vassell, W.C. Tribology International, v. 30, p. 9, 1997.

14. Jiang, L.; Chen, X.; Wang, X.; Xu, L.; Stubhan, F.; Merkel, K.-H. Thin Solid Films, v. 352, p. 97, 1999.

15. Wu, W.-J.; Hon, M.-H. Thin Solid Films, v. 345, p. 200, 1999.

16. Michler, J.; Tobler, M.; Blank, E. Diamond and Related
Materials, v. 8, p. 510, 1999.

17. Gangopadhyay, A.K.; Willermet, P.A.; Vassell, W.C.; Tamor, M.A. Tribology International, v. 30, p. 19, 1997.

18. De Martino, C.; Demichelis, F.; Tagliaferro, A. Diamond and Related Materials, v. 3, p. 547, 1994.

19. De Martino, C.; Fusco, G.; Mina, G.; Tagliaferro, A.; Vanzetti, L.; Calliari, L.; Andrele, M. Diamond and Releted Materials, v. 6, p. 559, 1997.

20. Hacskaylo, M. Journal of the Optical Society of America, v. 54, n. 2, p. 198, 1964.

21. Zou, J.W.; Schmidt, K.; Reichelt, K.; Dischler, B. Journal of Applied Physics, v. 67, n. 1, p. 487-494, 1990.

22. Damasceno, J.C.; Camargo Jr., S.S.; Freire Jr., F.L.; Carius, R. Surface and Coatings Technology, v. 133-134, p. 247-252, 2000.

23. Robertson, J. Diamond and Related Materials, v. 3, p. 361-368, 1994.

24. Tamor, M.A.; Vassell, W.C.; Carduner, K.R. Applied Physics Letters, v. 58, n. 6, p. 592-594, 1991. 